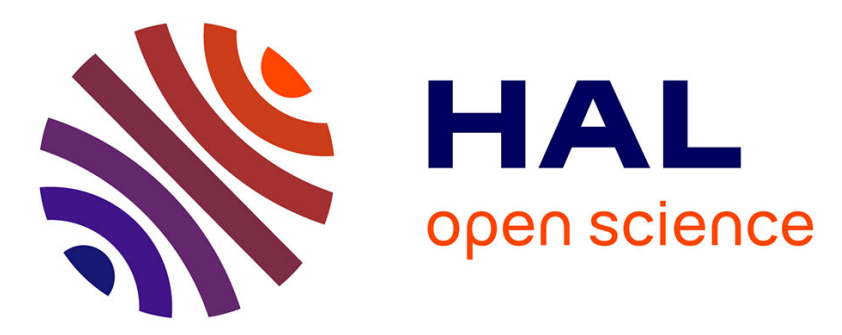

\title{
Age-related changes in auditory temporal processing in the rat
}

Daniel Šuta, Natalia Rybalko, Jana Pelánová, Jiří Popelář, Josef Syka

\section{To cite this version:}

Daniel Šuta, Natalia Rybalko, Jana Pelánová, Jiř́ Popelář, Josef Syka. Age-related changes in auditory temporal processing in the rat. Experimental Gerontology, 2011, 46 (9), pp.739. 10.1016/j.exger.2011.05.004 . hal-00720178

\section{HAL Id: hal-00720178 https://hal.science/hal-00720178}

Submitted on 24 Jul 2012

HAL is a multi-disciplinary open access archive for the deposit and dissemination of scientific research documents, whether they are published or not. The documents may come from teaching and research institutions in France or abroad, or from public or private research centers.
L'archive ouverte pluridisciplinaire HAL, est destinée au dépôt et à la diffusion de documents scientifiques de niveau recherche, publiés ou non, émanant des établissements d'enseignement et de recherche français ou étrangers, des laboratoires publics ou privés. 


\section{Accepted Manuscript}

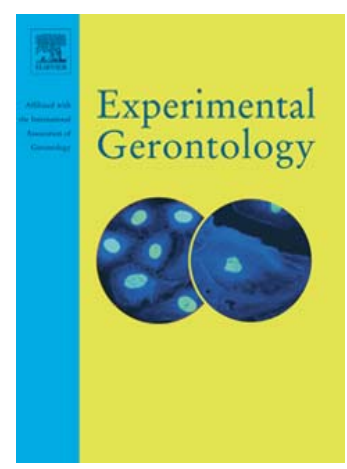

Age-related changes in auditory temporal processing in the rat

Daniel Šuta, Natalia Rybalko, Jana Pelánová, Jiří Popelář, Josef Syka

PII: $\quad$ S0531-5565(11)00124-0

DOI: doi: $10.1016 /$ j.exger.2011.05.004

Reference: $\quad$ EXG 8883

To appear in: $\quad$ Experimental Gerontology

Received date: $\quad 4$ March 2011

Revised date: $\quad 9$ May 2011

Accepted date: 10 May 2011

Please cite this article as: Šuta, Daniel, Rybalko, Natalia, Pelánová, Jana, Popelář, Jiř́i, Syka, Josef, Age-related changes in auditory temporal processing in the rat, Experimental Gerontology (2011), doi: 10.1016/j.exger.2011.05.004

This is a PDF file of an unedited manuscript that has been accepted for publication. As a service to our customers we are providing this early version of the manuscript. The manuscript will undergo copyediting, typesetting, and review of the resulting proof before it is published in its final form. Please note that during the production process errors may be discovered which could affect the content, and all legal disclaimers that apply to the journal pertain. 
Age-related changes in auditory temporal processing in the rat

Daniel Šuta ${ }^{1,2}$, Natalia Rybalko ${ }^{1}$, Jana Pelánová ${ }^{1}$, Jiří Popeláŕ ${ }^{1}$, Josef Syka $^{1}$

${ }^{1}$ Department of Auditory Neuroscience, Institute of Experimental Medicine, Academy of Sciences of the Czech Republic, Prague, Czech Republic

${ }^{2}$ Department of Medical Biophysics and Medical Informatics, Third Faculty of Medicine, Charles University, Prague, Czech Republic

Corresponding author: Daniel Šuta, $\mathrm{PhD}$

Institute of Experimental Medicine,

Academy of Sciences of the Czech Republic

Vídeňská 1083

14220 Prague 4

Czech Republic

E-mail: suta@biomed.cas.cz

Phone: (+420) 241062689

Fax: (+420) 241062787 


\section{ABSTRACT}

Presbycusis, as the deterioration of hearing ability occurring with aging, can be manifested not only in a shift of hearing thresholds, but also in a deterioration of the temporal processing of acoustical signals, which may in elderly people result in degraded speech comprehension. In this study we assessed the age-related changes in the temporal processing of acoustical signals in the auditory system of pigmented rats (Long Evans strain). The temporal resolution was investigated in young adult (3-4 months) and old (30-34 months) rats by behavioral and electrophysiological methods: the rats' ability to detect and discriminate gaps in a continuous noise was examined behaviorally, and the amplitude-rate function was assessed for the middle latency response (MLR) to clicks. A worsening of the temporal resolution with aging was observed in the results of all tests. The values of the gap detection threshold (GDT) and the gap duration difference limen (GDDL) in old rats increased about two-fold in comparison with young adult rats. The MLR to a click train in old rats exhibited a significantly faster reduction in amplitude with an increasing stimulation rate in comparison with young adult rats. None of the age-related changes in the parameters characterizing temporal resolution (GDT, GDDL and MLR to a click train) correlated with the degree of the age-related hearing loss. However, the age-related changes in MLR amplitude-rate function correlated with the age-related changes in GDDL, but not with the changes in GDT. The behavioral and electrophysiological data clearly show that aging in rats is accompanied with a pronounced deficit in the temporal processing of acoustical signals that is associated with the deteriorated function of the central auditory system.

KEYWORDS: aging, gap detection, gap duration discrimination, middle latency response, stimulation rate, auditory temporal resolution. 


\section{INTRODUCTION}

Within the elderly segment of society, hearing deterioration is one of the most significant handicaps. Older people often experience difficulty in understanding speech, which may also appear in subjects without a significant hearing loss. Speech perception has been widely studied in connection with the temporal resolution of the auditory system. Many researchers have found a significant relationship between abnormalities in temporal processing and a deterioration of speech perception [1-6].

Gap detection threshold (GDT) and gap duration difference limen (GDDL) are usually used as indices of auditory temporary resolution in man [1, 7-12]. GDT is the smallest duration of a silent interval in a sound that a subject is able to detect; GDDL is defined as the smallest change in the duration of a silent interval that a subject may discriminate from the duration of another interval. A significant deficit in gap detection $[4-6,13,14]$ as well as in gap discrimination $[11,12,15,16]$ has been shown in older people.

Age-related changes in temporal processing in the auditory system have also been studied in animal models. As a behavioral method for assessing auditory temporal resolution in animals, the gap detection task has been frequently used (e.g., rat [17-19], mice [20, 21], chinchilla [22, 23]; ferret [23], gerbil [25], starling [26], budgerigar and zebra finch [27]. A deficit in gap detection with aging was demonstrated in mice [20, 28] and gerbils [29].

Another approach to studying the problem of age-related changes in auditory temporal resolution is the use of electrophysiological methods, when either neuronal activity or evoked potentials are recorded in response to a gap in noise or to two acoustic stimuli separated by various gaps [28, 30-33] or to a train of acoustical stimuli with different repetition rates [3437]. The results of electrophysiological studies have demonstrated abnormal temporal processing in the central auditory system of aged animals [28, 31, 33, 36, 38, 39]. 
The purpose of our study was to assess the age-related changes in auditory temporal resolution in rats of the Long-Evans strain. Long Evans rats, with a life-span of about three years and with a relatively slowly-progressing hearing impairment with age, represent a suitable model for investigating presbycusis [40]. In contrast to the Fischer 344 strain, which is frequently used as a model of fast aging (see [41] for a review), Long-Evans rats serve as a model of relatively normal aging. Three different measures of temporal auditory resolution were used in the study: i) GDT, ii) GDDL and iii) MLR amplitude-rate function for click stimulation. The tests were performed in a group of young (three months old) and a group of aged (30-34 months old) animals. The parameters characterizing temporal auditory resolution were compared with each other and were also related to the degree of hearing loss.

\section{METHODS}

\subsection{Subjects}

Twelve female pigmented rats (strain Long Evans) with no primary pathology, weighing about 250 grams, were used in the aging experiment. At the age of 3-4 months the rats were divided into two groups: 6 animals were trained and tested to detect gaps in a continuous noise (GDT) (Fig. 1A) and 6 animals were trained and tested to discriminate between gaps with different durations (GDDL) (Fig. 1B). Subsequent measurements of GDT in the rats of the first group and GDDL in the rats of the second group were performed at the age of 30-34 months. Because one rat of the first group died before the age of 30 months, the retest of GDT in aged animals was conducted only in 5 rats. All animals were housed under standard laboratory conditions, 2-3 rats in a cage with a constant climate and a 12/12 h normal light/dark cycle. Animals had free access to food and water (except during behavioral training when they were restricted in access to water). The measurements of GDT and GDDL in old rats required their additional training. The experimental conditions of the additional training 
were the same as in the initial training. At the end of the behavioral experiment, middle latency responses (MLR) to acoustical stimuli were recorded to evaluate age-related hearing loss and changes in the recovery function of cortical evoked activity. The MLR thresholds measured in old rats were compared with the thresholds obtained in 20 control young rats 3-4 months old; in 8 of them the effect of the stimulus repetition rate on the MLR amplitudes was studied as well. Control animals were housed under standard laboratory conditions as described above.

All animal procedures were approved by the Animal Care Committee of the Institute of Experimental Medicine, Academy of Sciences of the Czech Republic, Prague, Czech Republic.

\subsection{Behavioral procedure and apparatus}

Behavioral experiments were conducted in a rat test cage (provided with a drinking apparatus and an optical licometer for the detection of licking) placed in an anechoic, soundproof room, which was described in detail previously [42]. The floor of the cage was connected to a precision regulated shocker, which was able to generate a level-adjustable electric footshock $(100-300 \mu \mathrm{A})$. Acoustical stimuli were presented from a SEAS T $25 \mathrm{CF}$ 002-06 loudspeaker placed $50 \mathrm{~cm}$ in front of the cage wall, where the apparatus for drinking water was also placed. The acoustic system was calibrated with a B\&K 4133 microphone, a ZC0020 preamplifier and a B\&K 2231 sound level meter; the microphone was placed in the position of the animal's head and facing the speaker. Variability in the animal's head position during acoustic stimulation was minimized because the stimulus was presented only when the animal was in contact with the spout. The frequency-response curve of the acoustic system was relatively flat and varied by less than $\pm 7 \mathrm{~dB}$ between 1 and $30 \mathrm{kHz}$. A video camera situated near the cage allowed visual monitoring of the subject's behavior during the 
experiment. The equipment for stimulus generation and response acquisition consisted of a TDT system 3 setup (RP2, PA5, HB7) connected to a PC. Stimulus presentation and data acquisition were controlled by Matlab custom-made software.

Using a conditioned avoidance response procedure, thirsty rats were trained to stop drinking when a stimulus was presented (paired with a mild electric shock when the animal did not stop drinking) and to continue drinking in the case of a "safe" stimulus. As test stimuli, a series of short silent periods (gaps) embedded in a continuous broad-band noise $(500 \mathrm{~Hz}-25$ $\mathrm{kHz}$ ) of $75 \mathrm{~dB}$ SPL intensity was used. For the gap detection task, the warning stimulus was a series of five gaps of $40 \mathrm{~ms}$ duration each, separated by $160 \mathrm{~ms}$ of noise; the safe stimulus was continuous noise with no gap (Fig. 1A). For the gap duration discrimination task, a series of five gaps of $60 \mathrm{~ms}$ duration each, separated by $140 \mathrm{~ms}$ of noise, served as the warning stimulus. A series of five gaps of $15 \mathrm{~ms}$ duration each, separated by $185 \mathrm{~ms}$ of noise, served as the safe stimulus (Fig. 1B). One experimental session lasted about $20 \mathrm{~min}$ and consisted of up to 150 trials, which were presented in a quasi-random manner with a ratio of warning trials to safe trials of 1:1.8. A warning trial was never followed by another warning trial. Each trial started only if the animal was licking and consisted of stimulus presentation and the response period $(500 \mathrm{~ms})$ during which the rat's licking was detected. Intervals between trials were random in the range of $500-1500 \mathrm{~ms}$.

The animal's performance was evaluated on the basis of hit and false alarm statistics. The cessation of licking in response to a "warning" stimulus was classified as a hit response; the cessation of licking in response to a "safe" stimulus was considered as a false alarm response (Fig. 1 A, B). At the end of the session the hit rate was calculated as the number of hit responses divided by the total number of "warning" stimuli, and similarly the false alarm rate was calculated as the number of false alarm responses divided by the total number of "safe" stimuli. Then, the performance as a single parameter characterizing the ability to detect or 
discriminate stimuli was calculated by the formula: performance $=$ hit rate - hit rate $\mathrm{x}$ false alarm rate and expressed as a percentage [43]. An excellent performance with a hit rate close to $100 \%$ and rarely occurring false alarms is characterized by performance values near $100 \%$. In contrast, when an animal is unable to detect or discriminate stimuli, the hit rate and false alarm rate values are similar and the performance value is $0-25 \%$ (a chance level of performance). The training period lasted until the performance reached a steady level and further prolongation of the training did not lead to any improvement in performance. The final performance was then calculated as the mean performance of the last four training sessions. When the behavioral training was completed and the final performance was determined, GDT and GDDL were measured in the rats of the first and second groups, respectively. The threshold values for detection or discrimination were determined using a method of constant stimuli. Data for the determination of GDT were collected using silent gaps of 1.5-10 ms duration, presented in random order. GDT was determined as the value of the gap duration that resulted in 50\% performance in the psychophysical curve. In the gap duration discrimination task, GDDL was assessed for two different values of the reference gap durations: 15 and $40 \mathrm{~ms}$, which served as the "safe" stimulus in the testing procedure. The tested gap served as the "warning" stimulus, was longer than the reference gap, and approached the reference gap during the experiment. GDDL was determined as the value of the difference between the "safe" and "warning" gap durations that resulted in 50\% discrimination performance. Temporal sensitivity in the discrimination task was also presented in terms of Weber's ratio, calculated as the GDDL divided by the value of the reference gap duration.

\subsection{Electrophysiological procedure}


Electrophysiological recording of the middle latency response (MLR) was performed in all old rats $(n=11)$ after the behavioral experiments were finished and in a control group of young rats $(n=20)$. The animals were anesthetized with an intramuscular injection of 35 $\mathrm{mg} / \mathrm{kg}$ of ketamine (Narkamon $5 \%$, Spofa) and $6 \mathrm{mg} / \mathrm{kg}$ of xylazine (Sedazine, Fort Dodge Inc.). A single dose of anesthetic was sufficient for the surgery and recording, because the whole experiment lasted less than 1 hour. MLRs were recorded with a teflon-coated platinum iridium ball electrode (diameter $0.5 \mathrm{~mm}$ ) placed on the surface of the left auditory cortex through a small hole ( $2 \mathrm{~mm}$ in diameter) in the bone and fixed to the bone by duracryl (Spofa Dental). The reference electrode was placed in the neck muscles.

The assessment of hearing thresholds was done using tone bursts ( $3 \mathrm{~ms}$ duration, $1 \mathrm{~ms}$ rise-fall time, $2 \mathrm{~s}^{-1}$ repetition rate, $\mathrm{n}=30$ ) in the frequency range of $1-32 \mathrm{kHz}$ with $5 \mathrm{~dB}$ intensity steps. The threshold was defined as the lowest stimulus level that produced a visually detectable response, consisting of the $\mathrm{N}_{1}, \mathrm{P}_{2}$ and $\mathrm{N}_{2}$ components within an interval of 10-70 ms [44].

MLR amplitude vs. click rate function was evaluated for clicks of $70 \mathrm{~dB}$ SPL intensity with a repetition rate of $1-15 \mathrm{~s}^{-1}$. The relative MLR amplitude was calculated as $\mathrm{P}_{2}-\mathrm{N}_{2}$ (peakto-peak) voltage divided by the MLR magnitude for a stimulus rate of $1 \mathrm{~s}^{-1}$ and was expressed as a percentage. The limit of the MLR temporal resolution was determined as the maximal stimulus repetition rate for which the $\mathrm{P}_{2}-\mathrm{N}_{2}$ wave complex was detectable.

Recording was performed in an anechoic sound-proof room. Stimuli were presented in free-field conditions from a two-way loudspeaker system (Jamo woofer and SEAS T25CF 002 tweeter), which was placed $70 \mathrm{~cm}$ in front of the animal's head. Calibration of the sound field was performed with a B\&K microphone (4939), a ZC0020 preamplifier and a B\&K 2231 sound level meter; the microphone was placed in the position of the animal's head and facing the speaker. Stimulus generation and MLR acquisition were performed by a TDT 
system3 setup (RP2 and RX-5 Pentusa real-time processors, RA 16 PA preamplifier) and a PC computer running BioSig software.

\section{RESULTS}

\subsection{Gap detection in young adult and old rats}

Young adult rats of the first group (aged 3-4 months, $n=6$ ) were trained to detect gaps in a continuous noise. Individual rats needed 2-4 training sessions to reach a steady level of performance; subsequent training did not significantly improve their performance in the gap detection task. During the training, the performance values increased from $38.8 \pm 16.8 \%$ in the first day to $78.4 \pm 4.3 \%$ at the best performance level. After reaching a steady level of performance, their gap detection ability was assessed in trained animals. An example of the psychometric functions used for the determination of the GDT value in a young adult animal is shown in Fig.2A. GDTs in individual rats ranged from 1.7 to $2.0 \mathrm{~ms}$ with an average of $1.8 \pm 0.1 \mathrm{~ms}$ (Fig. 2).

Gap detection ability was studied in the same animals again at the age of 30-34 months. Additional training was necessary prior to the GDT measurements in old rats. Already in the first session of the additional training, the rats reached a performance of $50.7 \pm 7 \%$, which was higher than their performance in the first session of the initial training. All old rats reached a steady level of performance $(75.2 \pm 6 \%$ performance $)$ on the third training day. GDTs in old rats were in the range of $2.7-4.0 \mathrm{~ms}$ with an average of $3.4 \pm 0.5 \mathrm{~ms}$. This value represents a significant increase $(\mathrm{P}<0.0001$; unpaired $\mathrm{t}$-test $)$ in comparison with the GDT in young-adult animals (Fig.2). GDT values in old rats were significantly more variable than those obtained in young animals ( $\mathrm{P}=0.03$, F test; Fig. 2B).

\subsection{Discrimination of gap duration in young adult and old rats}


Young adult rats in the second group (aged 3-4 months, $n=6$ ) were trained to discriminate between gaps of different durations. The training period for the discrimination task was longer than the training period for the detection task. To complete the training for the discrimination task, individual rats needed 3-8 sessions. During training their performance increased from $36.2 \pm 14.3 \%$ on the first day to the final performance of $75.6 \pm 7.8 \%$.

Two values of the reference gap duration, i.e. $15 \mathrm{~ms}$ and $40 \mathrm{~ms}$, were used to assess the gap discrimination ability (Fig 3). Average GDDLs in young-adult rats for the reference gap durations of $15 \mathrm{~ms}$ amounted to $5.8 \pm 1.1 \mathrm{~ms}$ and for the reference gap durations of $40 \mathrm{~ms}$ amounted to $17.5 \pm 2.4 \mathrm{~ms}$ (Fig.3A). Temporal discrimination in young adult animals expressed as the Weber's ratio (calculated as the GDDL values divided by the reference gap duration) was similar for the reference gaps of $15 \mathrm{~ms}$ and $40 \mathrm{~ms}(\mathrm{p}>0.05$, paired t-test, Fig.3B).

The ability to discriminate gap duration was evaluated in the same animals again at the age of 30-34 months. Similarly as in the case of GDT, additional training was necessary before the final GDDL measurement. Old rats achieved a relatively good performance $(43.3 \pm 9 \%)$ already in the first session of the additional training. The rats needed $4-5$ sessions to reach a final steady performance level of $70.3 \pm 8 \%$.

The ability to discriminate gap duration was worse in old rats than in young-adult rats. GDDL in old rats increased almost two-fold in comparison with young adult rats and reached $11.1 \pm 1.4 \mathrm{~ms}$ and $26.1 \pm 2.2 \mathrm{~ms}$ for the gap reference durations of $15 \mathrm{~ms}$ and $40 \mathrm{~ms}$, respectively ( $<<0.001$, unpaired t-test) (Fig. 3A). The increase of the GDDL with age was more pronounced when the smaller reference gap duration was used: old animals' GDDL increased by $49 \%$ for the longer reference gap of $40 \mathrm{~ms}$, while the increase was $91 \%$ for the shorter reference gap of $15 \mathrm{~ms}$. The Weber's ratios for $15 \mathrm{~ms}$ and $40 \mathrm{~ms}$ reference gap durations were significantly different in old rats $(\mathrm{p}=0.01$, two-tailed paired $\mathrm{t}$-test $)$. A considerable variability 
in GDDL was observed in both young and old rats. Unlike the results of the GDT test, the variance of the Weber's ratios between the different age groups was not significantly different ( $p>0.5$ for the gap reference duration of $15 \mathrm{~ms}$ and $\mathrm{p}>0.7$ for the gap reference duration of 40ms, respectively, F-test).

\subsection{Middle latency responses}

\subsubsection{MLR audiogram}

Hearing thresholds assessed with MLR to tonal stimuli were elevated in the old rats in comparison with the young control rats of the same strain by about 10-35 $\mathrm{dB}$ in the frequency range of 1-32 kHz. Average MLR hearing thresholds of the old rats (all animals of the first and second groups, $n=11)$ and the control group of young-adult rats $(n=8)$ are shown in Fig. 4.

\subsubsection{The effect of the stimulus repetition rate on MLR}

Temporal resolution was studied by recording the MLR to click trains of different rates. MLR amplitude in both young and old rats had a decreasing tendency with increasing stimulus repetition rate, as illustrated by the typical responses of a young and an old animal in Fig. 5A. In old rats the reduction of the MLR amplitude was more extensive and the decline started at lower click rates in comparison with the young rats (Fig. 5 A, B). While in young animals the MLR amplitudes were reduced with increasing click rate but the response remained clearly evident, in old animals the MLR completely disappeared - in some old rats at such a low click rate as 4 clicks/s. The decay in the number of old animals having a detectable MLR with an increasing click rate is illustrated in Fig. 5C. In none of the old rats were MLR present at the rate of 11 clicks/s. 


\section{Relationship between the changes in the parameters of auditory function in old rats}

For all the parameters of auditory function measured in old rats (GDT, GDDL at $15 \mathrm{~ms}$, GDDL at $40 \mathrm{~ms}$, maximal click rate evoking detectable MLR and hearing threshold), correlation coefficients were calculated to determine their contribution to the age-related changes. None of the parameters correlated significantly with the hearing threshold at either 8 or $32 \mathrm{kHz}\left(\mathrm{R}^{2}=0.03-0.13\right.$, the slope of the regression line did not differ significantly from zero, $\mathrm{P}>0.1$; see Table $\mathrm{S} 1$ of Supplementary Material for details).

The comparison between the behavioral parameters (GDT, GDDL at $15 \mathrm{~ms}$ and at $40 \mathrm{~ms}$ ) and the electrophysiological parameters (the maximal click rate evoking MLR) showed a significant correlation between the maximal click rate evoking MLR and GDDL at $15 \mathrm{~ms}$ as well as at $40 \mathrm{~ms}$ : worse temporal discrimination, manifested by a larger GDDT value, corresponded with a lower value of the maximal stimulus rate evoking MLR $\left(\mathrm{R}^{2}=0.75\right.$ and 0.76 , the slope of the regression line differed significantly from zero, $\mathrm{P}=0.02$ in both cases, Fig. 6, Table S2 of the Supplementary Material). In contrast, the correlation between the maximal click rate evoking MLR and the GDT value was not found to be significant $\left(\mathrm{R}^{2}=0.08\right.$, the slope of the regression line did not differ significantly from zero, $\mathrm{P}=0.63$, Table $\mathrm{S} 2$ of the Supplementary Material).

\section{DISCUSSION}

The results of the present study clearly demonstrate the age-related decline in the temporal processing of auditory signals in the rat. All three parameters used to evaluate temporal resolution in the auditory system of rats point to a worsening of temporal sensitivity: the gap detection threshold and the gap duration difference limen were found to be prolonged by age and the amplitude-rate function of the MLR to click exhibited the suppression of the MLR, starting already at low repetition rates. 
The results of the gap detection measurements showed the same GDT values in young adult rats as we found in previous experiments $[18,19]$, with a significant worsening of the GDT values in old rats when they increased almost two-fold (by 89\%). The age-related increase in the gap detection threshold (1.8 $\mathrm{ms}$ in young and $3.4 \mathrm{~ms}$ in old rats) had a similar magnitude as reported in mice [28], gerbils [29] and man [4, 5, 10, 14]. For example, the mean GDT values for young and old gerbils were $2.6 \mathrm{~ms}$ and $4.3 \mathrm{~ms}$, respectively [29], and for young and old human subjects the mean GDT values were 2.8 and $6.7 \mathrm{~ms}$, respectively [14]. These data support the idea that the age-related deficit in gap detection may have a common mechanism in mammals of different species.

The individual variability of GDTs was considerably larger in old rats in comparison with young rats. The same phenomenon of increased GDT variability in elderly subjects was also observed in gerbils [29], mice [28] and in man [9, 28]

Several studies have demonstrated that the intensity and frequency content of the carrier noise play an important role in gap detection: GDT values markedly increase (both in man and in animals) when the signal audibility is low (when the noise intensity is less than 25-30 $\mathrm{dB}$ sensation level) or when the noise spectrum is restricted to low frequencies $[1,8,18,45]$. The elevation of hearing thresholds may in principle result in a decrease of signal audibility, which in turn leads to a worsening of gap detection. Similarly as in normal hearing subjects, an intensity of the carrier sound above a $20-30 \mathrm{~dB}$ sensation level is required for reliable GDT measurements in old [29] as well as in hearing-impaired subjects [18, 46]. With respect to the results of our previous study [47] and the results of other authors showing that the increase of hearing thresholds in old rats amounts to $30-40 \mathrm{~dB}[34,48,49]$, we measured GDT and GDDL at a carrier noise intensity of $75 \mathrm{~dB}$ SPL. This was a sufficient intensity to minimize the contribution of the $35 \mathrm{~dB}$ threshold shift in old animals and to ensure optimal conditions for gap detection. 
Temporal sensitivity in the rats, characterized by the gap duration discrimination limen, also deteriorated with age. The ability to discriminate between gaps of different duration was significantly better in the young rats in comparison with old rats: the mean Weber's ratios were 0.39 and 0.44 for young rats and 0.65 and 0.74 for old rats. Although there is a lack of animal studies focused of gap duration discrimination, our data correspond with the results of psychophysical studies in humans that show an age-related deficit in the ability to discriminate between gaps of different durations $[11,12,15,16,50,51]$, e.g. Fitzgibbons and Gordon-Salant [16] reported in humans Weber's ratios (to tonal stimuli) of 0.33-0.45 in younger subjects and 0.52-0.64 in older subjects, which are similar to the values we found in rats.

We found worse relative temporal discrimination values (larger Weber's ratio) for shorter reference duration in old rats. While the values of the Weber's ratio for $15 \mathrm{~ms}$ and $40 \mathrm{~ms}$ reference durations were similar in young rats, they differed in old rats: the Weber's ratio for $15 \mathrm{~ms}$ was significantly larger than that for $40 \mathrm{~ms}$. Our finding corresponds with the results of Fitzgibbons and colleagues, who also reported that the largest age-related changes were associated with the shortest reference duration $[15,16,50]$.

Age-related changes in temporal processing were also apparent in the electrophysiological part of our experiments. We observed a decrease in the MLR amplitudes with increasing stimulus repetition rate, which was more extensive and occurred at lower repetition rates in old rats in comparison with young animals. While MLRs in old rats already disappeared at stimulation rates of 4-10 $\mathrm{s}^{-1}$, it was possible to detect the main MLR components in all young rats minimally at a click rate of $15 \mathrm{~s}^{-1}$. This finding indicates that the cortical processing of rapidly recurring sounds is impaired with age.

Data about the influence of age on the rate effect of the auditory evoked responses are not uniform due to various technical parameters of the stimulation and recording, the subjects 
used and their state. Basically, it is known that the amplitude of evoked potentials depends at all levels of the auditory pathway on the stimulation rate - the amplitude decreases with increasing stimulation rate; this effect is amplified towards the auditory cortex $[52,53]$. Changes in the amplitude-rate function of the auditory evoked responses with age were reported at the level of the auditory brainstem in F344 rats by Backoff and Caspary [36]: they found the auditory brainstem response (ABR) morphology in old rats less well defined for high rate stimuli $\left(5-50 \mathrm{~s}^{-1}\right)$ with the greatest degradation seen in the later ABR waves . In contrast, Boettcher and colleges [37] found in gerbils that the stimulation rate effect is not influenced by age: an increase in the stimulation rate from $11 \mathrm{~s}^{-1}$ to $91 \mathrm{~s}^{-1}$ resulted in an approximately equal reduction of the ABR amplitudes in gerbils of different ages. An agerelated deficit in humans was found in recordings of ABR to double noise bursts separated by various gaps: older subjects had smaller ABR amplitudes in response to the second stimulus and more frequently no response to shorter gap durations [54]. Data about the effect of age and stimulation rate on the MLR have been mainly obtained in human studies. In elderly listeners a progressive change in the waveform pattern of MLRs was observed at faster stimulus repetition rates $[35,55,56]$. In contrast to our results, Chambers [35] found that the reduction of one of the MLR components $(\mathrm{Pa})$ with an increasing stimulus rate was much more pronounced in young subjects than in older subjects. It should be noted that the direct comparison of evoked potentials in man and in laboratory animals is complicated by differences in the wave generators; moreover, the differences in the results could be determined by the subjects' state: MLRs in humans were recorded during an awake state whereas the MLRs in our experiments were recorded in anaesthetized rats.

The auditory system is a complex, hierarchically organized system, and age-related pathological changes may occur at all levels - from the periphery (the inner ear) to the auditory cortex. The hearing threshold shift is a phenomenon attributable to a large extent to 
the peripheral component of presbycusis, which comprises mainly alterations of the inner and outer hair cells and/or the stria vascularis. A significant age-related hair cell loss connected with a pronounced hearing threshold shift was reported previously in different strains of rats [40, 57, 58] as well as in human [59]. Specifically in Long Evans rats, Popelář el al. [40] found relatively weak, but consistent outer hair cell loss (10-20\%) in the middle part of the cochlea in aged animals (30 months old), which progressively increased towards the apical and basal ends of the cochlea where the outer hair cell loss reached $60-100 \%$. The number of missing inner hair cells was very low and did not exceed $10 \%$ with the exception of the basal end of the cochlea.

The central component of presbycusis (i.e., age-related changes occurring within the central auditory system) is thought to be associated with age-related alterations in the processing of complex acoustical stimuli and could be manifested also in the deterioration of the temporal processing of acoustical stimuli. The results of our study revealed that none of the analyzed temporal parameters (GDT, GDDL or MLR amplitude-rate function) in aged animals correlated with the hearing threshold shift. Although an increase of the GDT in subjects with hearing loss was reported in several studies $[1,7,8,19]$, the GDT values and audiometric threshold shifts were not significantly correlated [4, 5, 60, 61]. Similarly as GDT values, also individual GDDL values did not correlate with the hearing threshold in old rats. Such a lack of correlation is consistent with the results of human studies showing that GDDL does not depend on hearing loss in younger subjects [15] or in older subjects [50, 51,62].

The lack of correlation between the parameters characterizing temporal processing and the hearing threshold indicates that the age-related changes in temporal processing are to some extent independent of the hearing threshold and that the temporal processing ability is influenced by other factors such as changes in brain function . However, it is still not known whether the age-related changes in the central auditory system are activity-dependent and 
primarily follow the deterioration of the sensory inputs with aging or whether they rather result from age-related changes occurring within the central auditory system [63, 64].

The presence of a significant correlation between the MLR changes and GDDL changes (both at $15 \mathrm{~ms}$ and $40 \mathrm{~ms}$ ) and a non-significant correlation between the MLR changes and GDT changes points at differences between the individual parameters used for characterizing temporal processing. Since the MLR reflects the activity of the primary auditory cortex [44], the effect of the acoustical stimulus rate on the complex of MLR waves characterizes temporal processing at the cortical level. The study by Rybalko and colleagues [42] using cortical deactivation revealed that temporal discrimination (GDDL) in the rat depends on cortical processing (specifically in the left hemisphere), while the GDT can be consolidated before the recovery of the auditory cortex and is therefore based mostly on sub-cortical processing. Thus, we assume that the significant correlation between the MLR results and the GDDL results observed in our experiments indicates that both these parameters characterize temporal processing at the cortical level.

Age-related hearing loss and hearing impairment (i.e. presbycusis) are among the major health problems of older people, and with the continuing increases in human longevity, the problem of presbycusis is growing. The deterioration of auditory perception with aging can be accompanied by two types of deficits. The first type of deficit is associated with elevated hearing thresholds. The second type of deficit is caused by the distortion of suprathreshold processing (impaired intensity, frequency and temporal discrimination). Such a deficit might be manifested, for example, in poor speech perception in humans or the poor recognition of complex environmental sounds, including species-specific vocalizations in animals. Our results demonstrate the presence of both types of auditory deficits in aged rats - the elevation of hearing thresholds and impaired temporal resolution - that did not correlate with each other. The mechanisms of the age-related deterioration in temporal processing remain unclear, but 
many indicators point to insufficient inhibition at both the cortical and subcortical levels of the central auditory system $[41,63]$. Further experiments are necessary to prove this hypothesis and eventually to identify tools to remedy this defect. A better characterization of the mechanisms underlying impaired temporal processing (and deficits in speech perception, in particular) could lead to an improvement in signal processing in hearing aids and to more appropriate aural rehabilitation in general.

ACKNOWLEDGEMENTS: The study was supported by GACR 309/07/1336, LC 554 and AV0Z50390512. 


\section{REFERENCES:}

[1] R. Tyler, Q. Summerfield, E. Wood, M. Fernandes, Psychoacoustic and phonetic temporal processing in normal and hearing -impaired listeners, J. Acoust. Soc. Am. 72 (1982) $740-52$.

[2] W.A. Dreschler, R. Plomp, Relations between psychophysical data and speech perception for hearing-impaired subjects. II, J. Acoust. Soc. Am.78 (1985) 1261-70.

[3] S. Gordon-Salant, P.J. Fitzgibbons, Temporal factors and speech recognition performance in young and elderly listeners, J. Speech Hear. Res. 36 (1993) 1276-85.

[4] B.A. Schneider, M.K. Pichora-Fuller, D. Kowalchuk, M. Lamb, Gap detection and the precedence effect in young and old adults, J. Acoust. Soc. Am. 95 (1994) 980-91.

[5] K.B. Snell, D.R. Frisina, Relationships among age-related differences in gap detection and word recognition, J. Acoust. Soc. Am. 107 (2000) 1615-26.

[6] J. Mazelová, J. Popelář, J.Syka, Auditory function in presbycusis: peripheral vs. central changes, Exp. Gerontol. 38 (2003) 87-94.

[7] P.J. Fitzgibbons, F.L. Wightman, Gap detection in normal hearing and hearing-impaired listeners, J. Acoust. Soc. Am. 72 (1982) 761-5.

[8] S. Buus, M. Florentine, Gap detection in normal and impaired listeners: The effect of level and frequency, in: A. Michelsen (Ed.), Time Resolution in Auditory System, Springer-Verlag, New York, 1985, pp 159-179.

[9] B. Moore, R. Peters, B. Glasberg, Detection of temporal gaps in sinusoids by elderly subjects with and without hearing loss, J. Acoust. Soc. Am. 92 (1992) 1923-32.

[10] K.B. Snell, Age-related changes in temporal gap detection, J. Acoust. Soc. Am. 101 (1997) 2214-20.

[11] J. Lister, J. Besing, J. Koehnke, Effects of age and frequency disparity on gap discrimination, J. Acoust. Soc. Am. 111 (2002) 2793-800. 
[12] J.H. Grose, J.W. Hall 3rd, E.J. Buss, Temporal processing deficits in the pre-senescent auditory system, J. Acoust. Soc. Am. 119 (2006) 2305-15.

[13] N.J. He, A.R. Horwitz, J.R. Dubno, J.H.Mills, Psychometric functions for gap detection in noise measured from young and aged subjects, J. Acoust. Soc. Am. 106 (1999) 96678.

[14] A. Strouse, D.H. Ashmead, R.N. Ohde, D.W. Grantham, Temporal processing in the aging auditory system, J Acoust Soc Am. 104 (1998) 2385-99.

[15] P.J. Fitzgibbons, S. Gordon-Salant, Age effects on measures of auditory duration discrimination, J Speech Hear Res. 37(1994) 662-70.

[16] P.J. Fitzgibbons, S. Gordon-Salant, Aging and temporal discrimination in auditory sequences. J Acoust Soc Am. 109 (2001) 2955-63.

[17] J.R. Ison, Temporal acuity in auditory function in the rat: reflex inhibition by brief gaps in noise, J. Comp. Physiol. Psychol. 96 (1982) 945-54.

[18] J. Syka, N. Rybalko, J. Mazelová, R. Druga, Gap detection threshold in the rat before and after auditory cortex ablation, Hear. Res. 172 (2002) 151-9.

[19] N. Rybalko, J. Syka, Effect of noise exposure on gap detection in rats, Hear. Res. 200 (2005) 63-72.

[20] J.R. Ison, P. Agrawal, J Pak, W.J. Vaughn, Changes in temporal acuity with age and with hearing impairment in the mouse: A study of the acoustic startle reflex and its inhibition by brief decrements in noise level, J. Acoust. Soc. Am. 104 (1998) 1696-704.

[21] J.P. Walton, R.D. Frisina, J.E. Ison, W.E. O'Neill, Neural correlates of behavioral gap detection in the inferior colliculus of the young CBA mouse. J. Comp. Physiol. 181 (1997) 161-176. 
[22] D.M. Giraudi, R.J. Salvi, D. Henderson, R.P. Hamernik, Gap detection by the chinchilla. J. Acoust. Soc. Am., 68 (1980) 802-6.

[23] R.J. Salvi, S. Arehole, Gap detection in chinchillas with temporary high-frequency hearing loss. J. Acoust. Soc. Am. 77 (1985) 1173-7

[24] J.B. Kelly, B.J. Rooney, D.P. Phillips, Effects of bilateral auditory cortical lesions on gap-detection thresholds in the ferret (Mustela putorius), Behav. Neurosci. 110 (1996) $542-50$.

[25] E. Wagner, G.M. Klump, I.Hamann, Gap detection in Mongolian gerbils (Meriones unguiculatus), Hear. Res. 176 (2003) 11-6.

[26] G.M. Klump, E.H. Maier, Gap detection in the starling (Sturnus vulgaris). I. Psychophysical thresholds, J. Comp. Physiol. A 164 (1989) 531-38

[27] K. Okanoya, R.J. Dooling, Detection of gaps in noise by budgerigars (Melopsittacus undulatus) and zebra finches (Poephila guttata), Hear. Res. 50 (1990) 185-92.

[28] K. Barsz, J.R. Ison, K.B. Snell, J.P. Walton, Behavioral and neural measures of auditory temporal acuity in aging humans and mice, Neurobiol. Aging 23 (2002) 565-78.

[29] I. Hamann, O. Gleich, G.M. Klump, M.C. Kittel, J. Strutz, Age-dependent changes of gap detection in the Mongolian gerbil (Meriones unguiculatus), J. Assoc. Res. Otolaryngol. 5 (2004) 49-57.

[30] A.Ya. Supin, V.V. Popov, Temporal resolution in the dolphin's auditory system revealed by double-click evoked potential study, J. Acoust. Soc. Am. 97 (1995) 2586-93.

[31] F.A. Boettcher, J.H. Mills, J.L. Swerdloff, B.L. Holley, Auditory evoked potentials in aged gerbils: responses elicited by noises separated by a silent gap, Hear. Res. 102 (1996) 167-78.

[32] L.A. Werner, R.C. Folsom, L.R. Mancl, C.L. Syapin, Human auditory brainstem response to temporal gaps in noise, J. Speech. Lang. Hear. Res. 44 (2001) 737-50. 
[33] J.P. Walton, Timing is everything: temporal processing deficits in the aged auditory brainstem. Hear. Res. 264 (2010) 63-9.

[34] W.A. Cooper, J.R. Coleman, E.H. Newton, Auditory brainstem responses to tonal stimuli in young and aging rat, Hear. Res. 43 (1990) 171-80.

[35] R.D. Chambers, Differential age effects for components of the adult auditory middle latency response, Hear. Res. 58 (1992) 123-31.

[36] P.M. Backoff, D.M. Caspary, Age-related changes in auditory brainstem responses in Fischer 344 rats: effects of rate and intensity, Hear. Res. 73 (1994) 163-72.

[37] R.D. Frisina, Subcortical neural coding mechanisms for auditory temporal processing. Hear. Res. 158 (2001) 1-27.

[38] J.P. Walton, H. Simon, R.D. Frisina, Age-related alterations in the neural coding of envelope periodicities. J. Neurophysiol. 88 (2002) 565-78.

[39] F.A. Boettcher, D.R. White, J.H. Mills, B.N. Schmiedt, Age-related changes in auditory evoked potentials of gerbils. III. Low-frequency responses and repetition rate effects, Hear. Res. 87 (1995) 208-19.

[40] J. Popelář, D. Groh, J. Pelánová, B. Canlon, J. Syka, Age-related changes in cochlear and brainstem auditory functions in Fischer 344 rats, Neurobiol. Aging 27 (2006) 490500.

[41] J. Syka, The Fischer 344 rat as a model of presbycusis, Hear Res. 264 (2010) 70-8.

[42] N. Rybalko, D. Šuta, J. Popelár̆, J. Syka, Inactivation of the left auditory cortex impairs temporal discrimination in the rat, Behav. Brain Res. 209 (2010) 123-30.

[43] R.S. Heffner, H.E. Heffner, Sound localization and use of binaural cues by the gerbil (Meriones unguiculatus), Behav. Neurosci. 102 (1988) 422-8.

[44] D.S. Barth, S. Di, Three-dimensional analysis of auditory-evoked potentials in rat neocortex, J Neurophysiol. 64 (1990) 1527-36. 
[45] M. Penner, Detection of temporal gaps in noise as a measure of the decay of auditory sensation, J. Acoust. Soc. Am. 61 (1977) 552-57.

[46] R.J. Irwin, L.K. Hinchcliff, S. Kemp, Temporal acuity in normal and hearing-impaired listeners, Audiology 20 (1981) 234-43.

[47] N. Rybalko, J. Popelář , G. Brožek, J. Syka, Auditory thresholds and frequency discrimination in pigmented rats of different ages. $2^{\text {nd }}$ Conference of the Czech Neuroscience Society, Prague (1996) 126.

[48] M.T. Turnock, J.M. Harrison, Effects of age on hearing in rats. J. Acoust. Soc. Am. 58, Suppl. 1 (1975) 90.

[49] E. Borg, Auditory thresholds in rats of different age and strain, A behavioral and electrophysiological study, Hear. Res. 8 (1982) 101-15.

[50] P.J. Fitzgibbons, S. Gordon-Salant, J. Barrett, Age-related differences in discrimination of an interval separating onsets of successive tone bursts as a function of interval duration, J. Acoust. Soc. Am. 122 (2007) 458-66.

[51] J.H. Grose, J.W. Hall 3rd, E. Buss, Gap duration discrimination in listeners with cochlear hearing loss: effects of gap and marker duration, frequency separation, and mode of presentation, J. Assoc. Res. Otolaryngol. 2 (2001) 388-98.

[52] H. Davis, T. Mast, N. Yoshie, S. Zerlin, The slow response of the human cortex to auditory stimuli: recovery process, Electroencephalogr. Clin. Neurophysiol. 21 (1966) 105-13.

[53] R.A. Butler, M. Spreng, W.D. Keidel. Stimulus repetition rate factors which influence the auditory evoked potential in man, Psychophysiology 5 (1969) 665-72.

[54] E.A. Poth, F.A. Boettcher, J.H. Mills, J.R. Dubno, Auditory brainstem responses in younger and older adults for broadband noises separated by a silent gap, Hear. Res. 161 (2001) 81-6. 
[55] J. Jerger, T. Oliver, R. Chmiel, Auditory middle latency response: a perspective. Semin. Hear. 9 (1988) 75-86.

[56] R.D. Chambers, S.K. Griffiths, Effects of age on the adult auditory middle latency response, Hear. Res. 51 (1991) 1-10.

[57] E.M. Keithley, M.L. Feldman, Hair cell counts in an age-graded series of rat cochleas, Hear. Res. 8 (1982) 249-262.

[58] J.G. Turner, D.M. Caspary, Comparison of two rat models of aging. Peripheral pathology and GABA changes in the inferior colliculus, in: J. Syka J, M.M. Merzenich (Eds), Plasticity And Signal Representation in The Auditory System. Kluwer Plenum, New York, 2005, pp 217-225.

[59] H.F. Schuknecht, M.R. Gacek, Cochlear pathology in presbycusis, Ann. Otol. Rhinol. Laryngol. 102 (1993) 1-16.

[60] B.A. Schneider, S.J. Hamstra, Gap detection thresholds as a function of tonal duration for younger and older listeners, J. Acoust. Soc. Am. 106 (1999) 371-80.

[61] A. Heinrich, B. Schneider, Age-related changes in within - and between-channel gap detection using sinusoidal stimuli, J. Acoust. Soc. Am. 119 (2006) 2316-26.

[62] R.A. Roberts, J.J. Lister, Effects of age and hearing loss on gap detection and the precedence effect: broadband stimuli, J. Speech Lang. Hear. Res. 47 (2004) 965-78.

[63] D.M. Caspary, L. Ling, J.G. Turner, L.F. Hughes, Inhibitory neurotransmission, plasticity and aging in the mammalian central auditory system, J. Exp. Biol. 211 (2008) 1781-91.

[64] J. Syka, Plastic changes in the central auditory system after hearing loss, restoration of function, and during learning, Physiol. Rev. 82 (2002) 601-36. 


\section{FIGURE LEGENDS:}

Fig. 1 Schematic drawing of the time diagrams of gap detection (A) and gap duration discrimination (B) tasks. See Methods for a full description.

Fig. 2. Gap detection in young and old rats. A. Examples of the psychometric functions used to determine the gap detection threshold in a young (open triangles) and an old rat (filled triangles); B. Mean values of the gap detection threshold in young (empty bar) and old (filled bar) rats. Mean values $\pm \mathrm{SD}$ are shown $(* * * \mathrm{P}<0.001$, unpaired t-test).

Fig. 3. Gap duration discrimination in young and old rats measured for reference gap durations of $15 \mathrm{~ms}$ and $40 \mathrm{~ms}$, respectively. A. Mean values of the gap duration difference limen in young (empty bar) and old (full bar) rats; B. Weber ratios for the discrimination of gap duration in young (empty bar) and old (full bar) rats. Mean values \pm SD are shown (** $\mathrm{P}<0.01$, unpaired t-test).

Fig. 4. Hearing thresholds measured by MLR recording in young (open symbols, $n=20$ ) and old (filed symbols, $\mathrm{n}=11$ ) rats. Mean values \pm SD are shown.

Fig. 5. The effect of the click rate on MLR in young and old rats. A. Examples of the MLR changes with increasing stimulation rate in a young (left column) and an old (right column) rat. B. The relative MLR amplitude vs. stimulus repetition rate function in young (open symbols) and old (filled symbols) rats. C. Percentage of animals with a detectable MLR at particular stimulus repetition rates in young (open symbols) and old (filled symbols) rats. Mean values $\pm \mathrm{SD}$ are shown $(* * \mathrm{P}<0.01$, unpaired $\mathrm{t}$-test $)$. 
Fig. 6 Relationship between the gap discrimination ability and maximal click rate evoking a detectable MLR in old rats ( $\mathrm{n}=6$ ). Individual values of GDDL (y-axis) are shown relative to the maximal click rate evoking a detectable MLR (x-axis) for two values of the reference gap: $15 \mathrm{~ms}$ (circles) and $40 \mathrm{~ms}$ (squares). Lines represent linear regression for data of $15 \mathrm{~ms}$ (solid line) and $40 \mathrm{~ms}$ (dashed line) reference gaps. 
A Gap detection task

WARNING SAFE

WARNING WAFE WARNING

STIMULUS DIIII

\begin{tabular}{lllc} 
RESPONSE & HIT & FALSE ALARM & response period \\
\cline { 2 - 3 } & & &
\end{tabular}

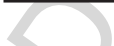

B Gap duration discrimination task

STIMULUS WARNING SAFE WARNING

RESPONSE

SHOCK

ת

Figure 1 


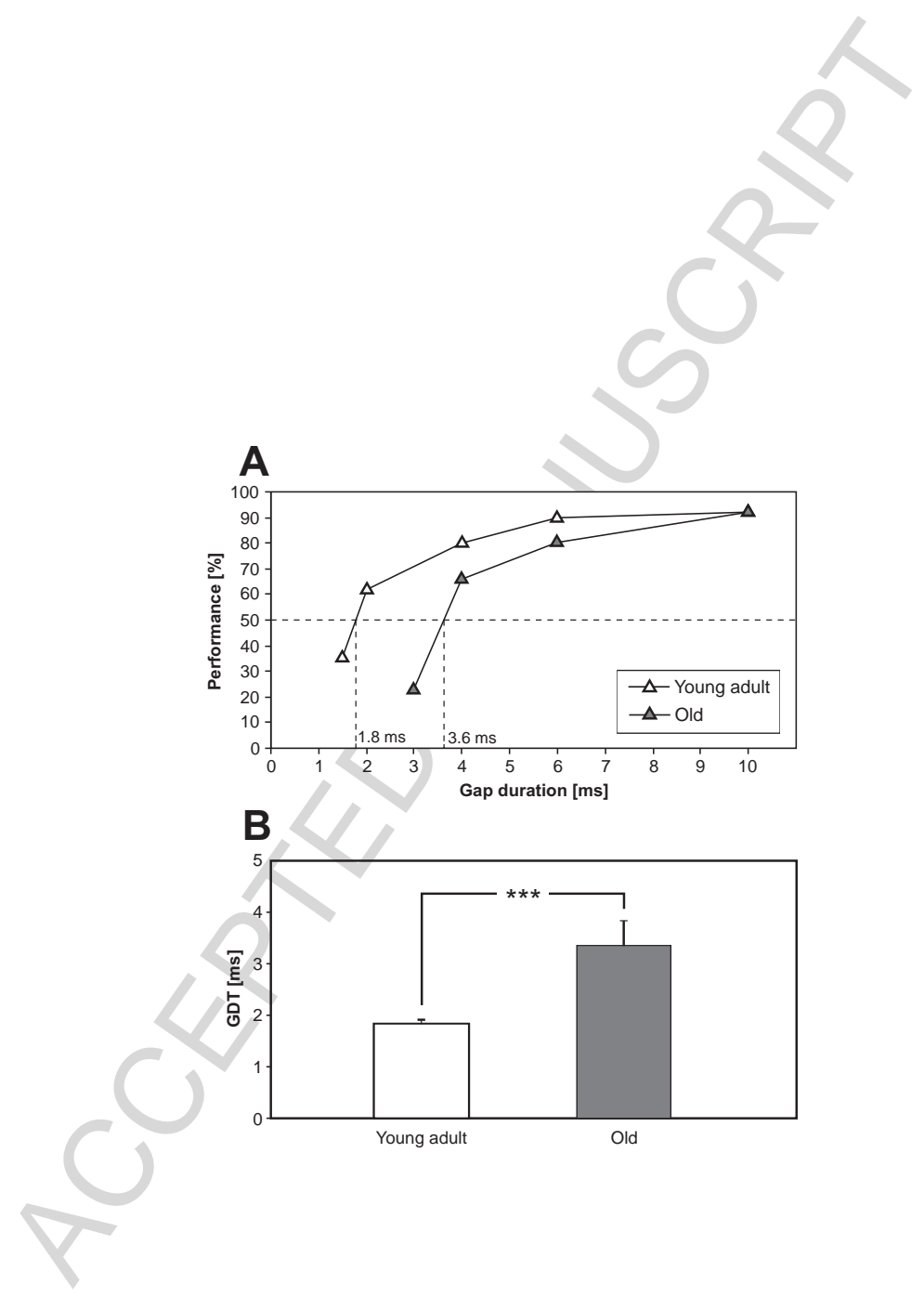

Figure 2 


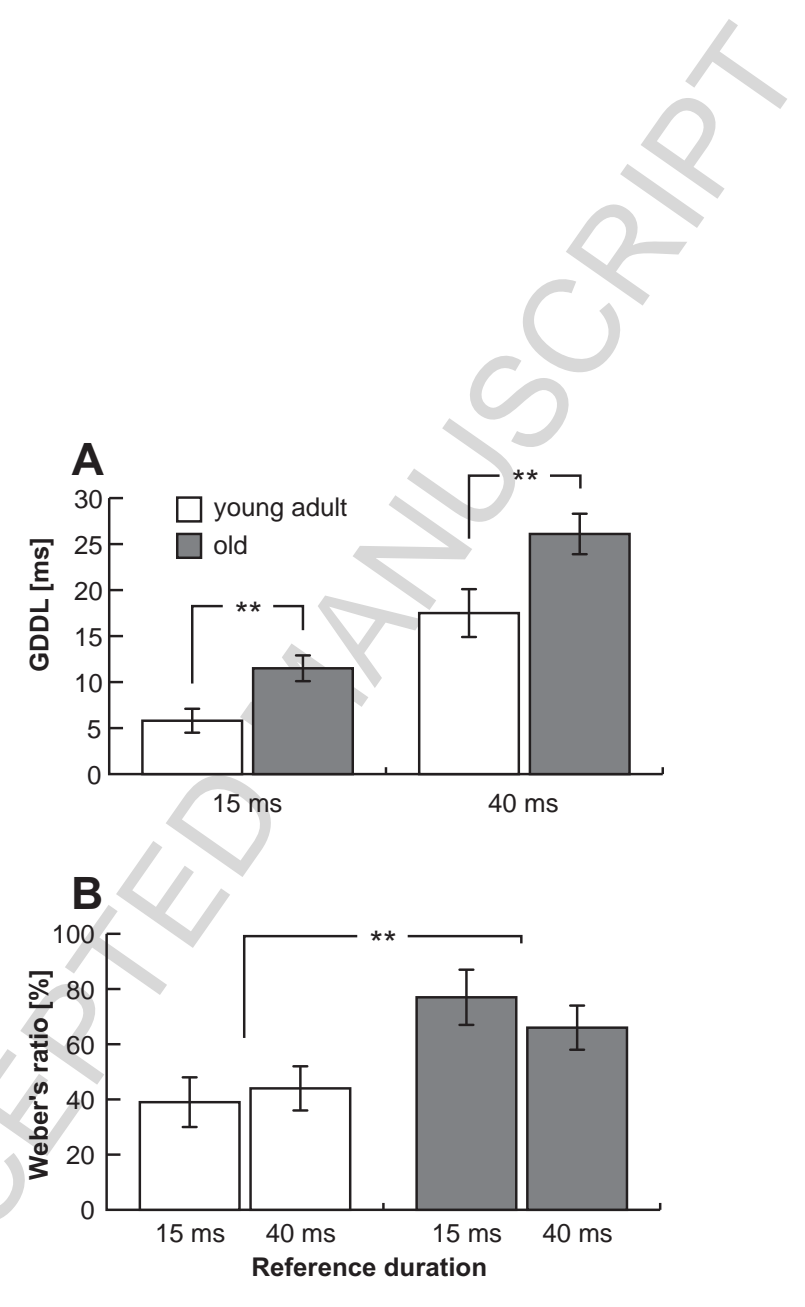

Figure 3 


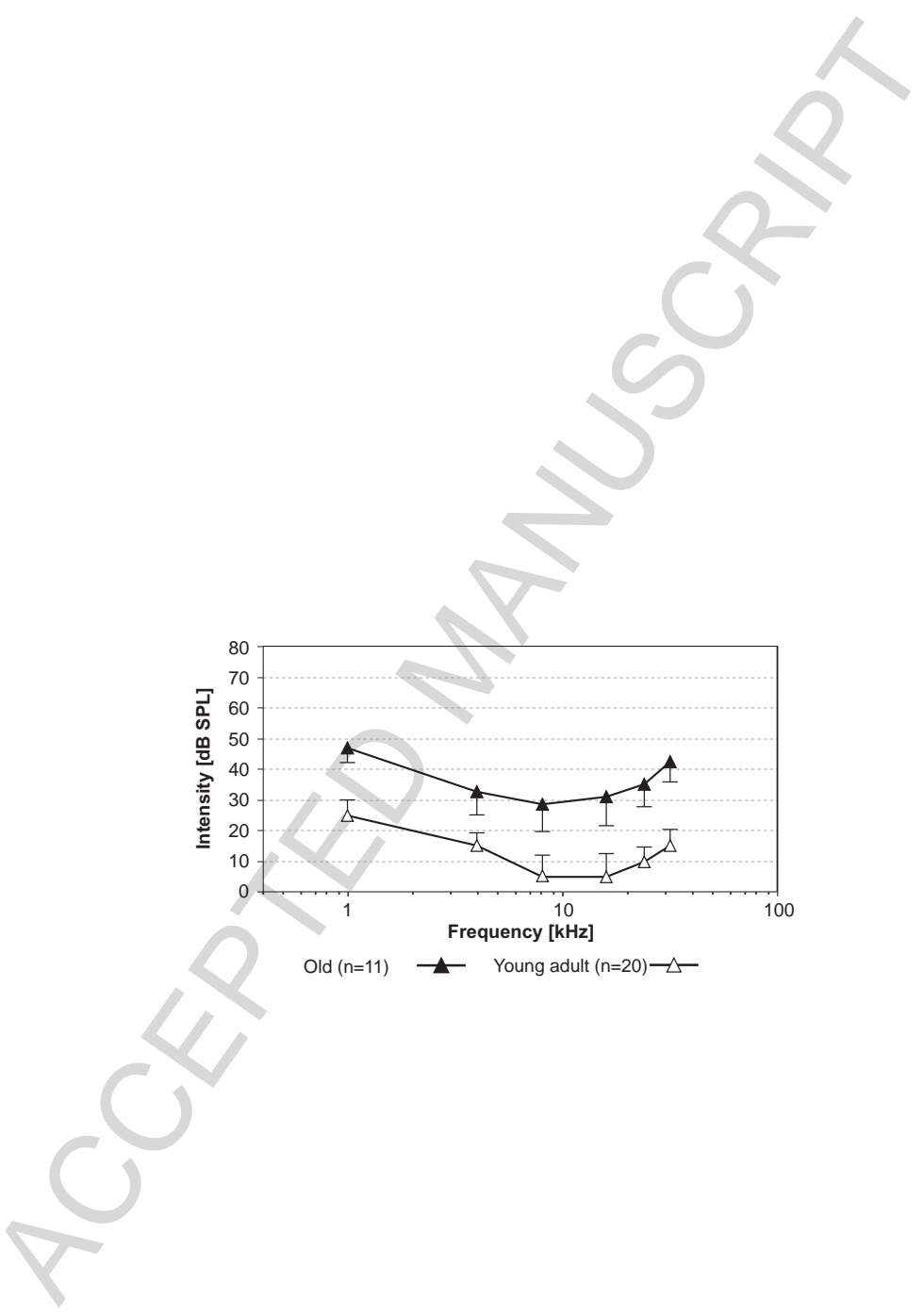

Figure 4 
A

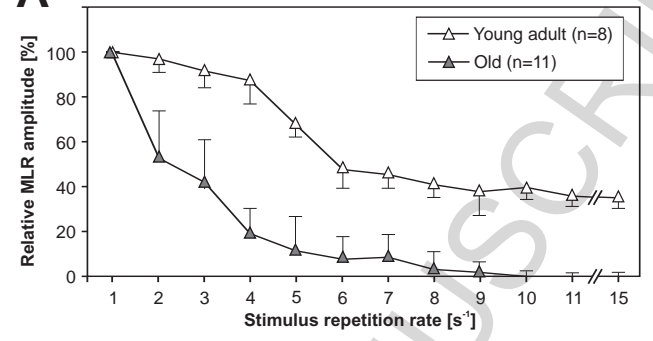

B

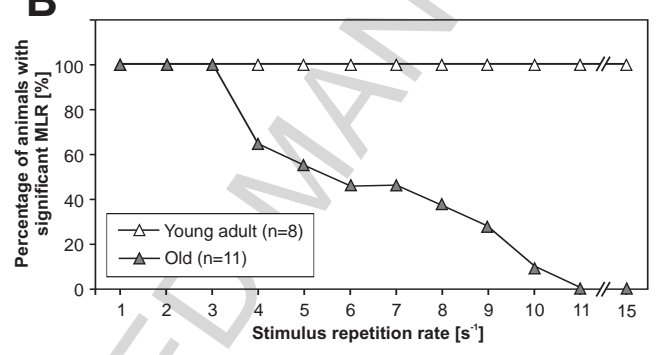

C

old young adult

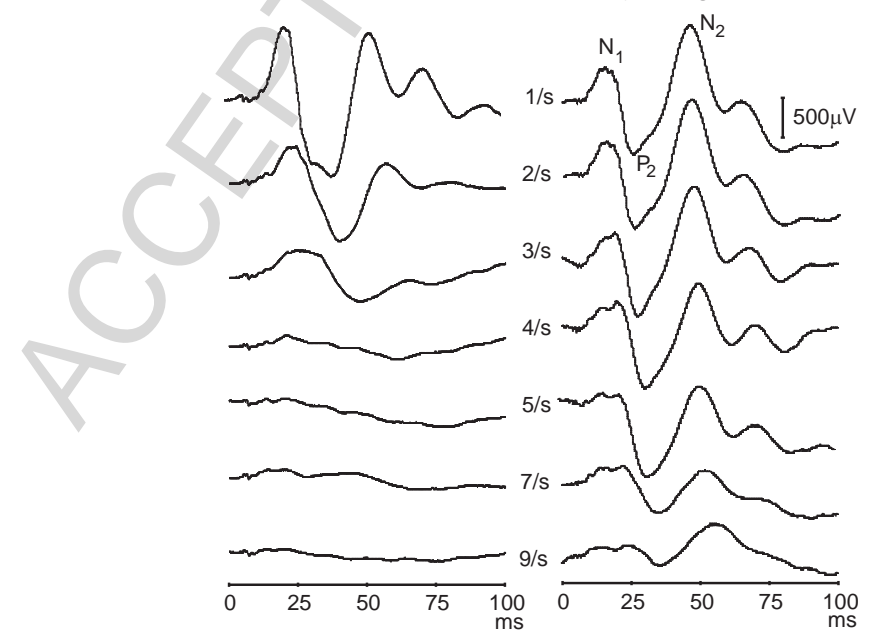

Figure 5 


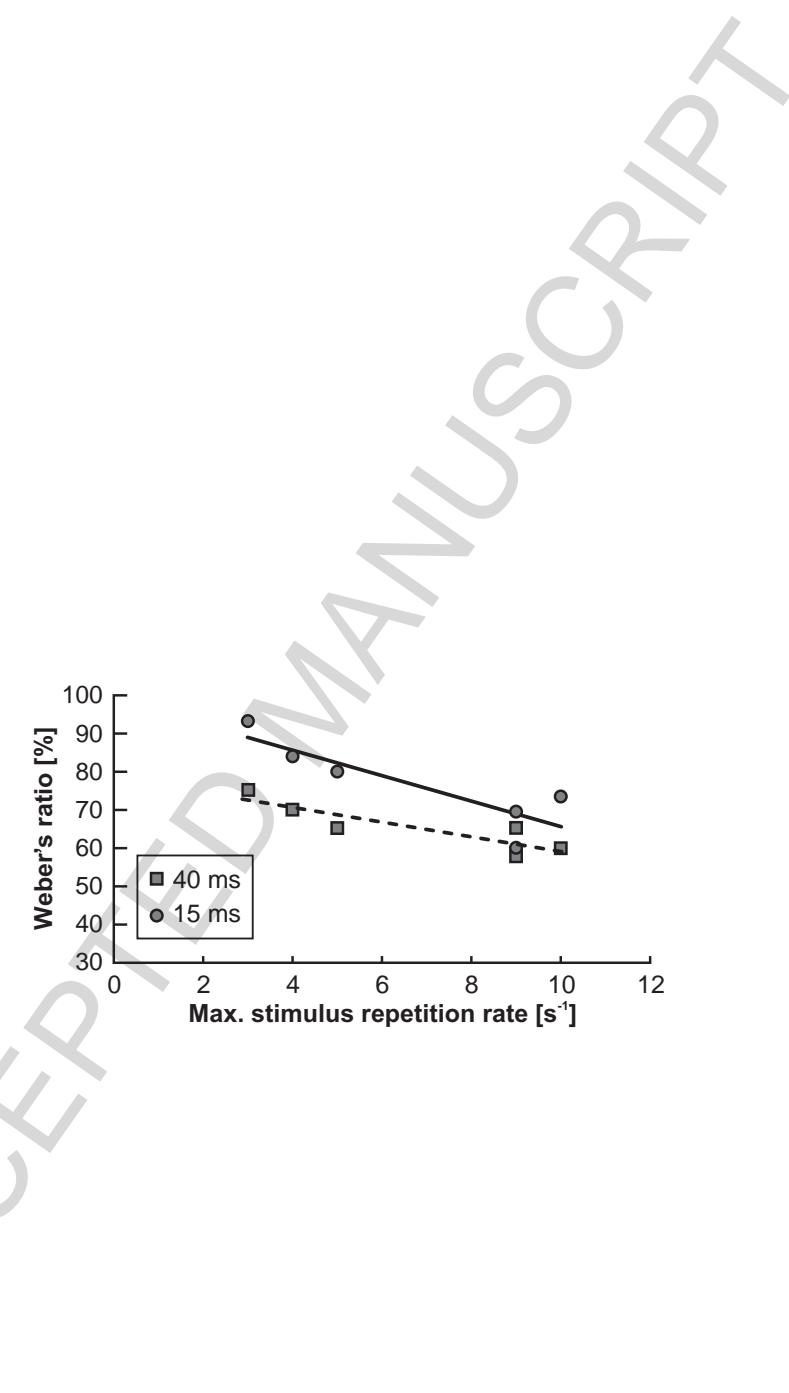

Figure 6 


\section{RESEARCH HIGHLIGHTS:}

- Significant age-related changes in temporal processing were observed in rats

- Old rats showed a deficit in their ability to detect and discriminate gaps in noise

- The MLR amplitude-rate function changed with age

- Age-related changes in MLR correlated with the changes in gap discrimination

- Deteriorated temporal processing in the rat did not correlate with hearing loss 